\title{
Practical Techniques for Cultural-based Language Teaching in the EFL Classroom
}

\author{
Lili Dai \\ Teachers College of Beijing Union University, 100011, Beijing, China \\ Email: sftlili@buu.edu.cn
}

\begin{abstract}
The present paper concerns itself with a study of the cultural-based language teaching issue, particularly with the issue of some practical techniques for teaching culture in the EFL classroom. We want to emphasize the importance of cultural acquisition in the study of language courses, and to present a range of practical techniques that have been found to be effective and successful in cultural-based courses and a few tips that can help to make the teaching of culture a better experience for both teachers and students. The purpose of this paper is to explore effective approaches of culture communication transmission in English classroom teaching.
\end{abstract}

Index Terms - language and culture, classroom teaching, practical techniques

\section{INTRODUCTION}

Every language is part of a culture. As such, it cannot but serve and reflect culture needs. (Hu Zhuanglin, 1988). There is a closed relation between language and culture, which are either the matrix or the reflection of culture. The world is now increasingly opening and various cultures blend with each other. Therefore, people with different culture have more and more mutual exchange and cooperation. For this reason, In EFL teaching, it is the most important task for teachers to have a through and profound grasp of language and culture in order to cultivate students' communicative competence and to develop teaching techniques.

With the research of the relationship between culture and language teaching deepening, people have realized the necessity of teaching culture into language learning. As we know, the cultural factors become more and more important in English teaching. A lot of experts are for the opinion that teaching language means teaching culture. The purpose of language learning is to equip learners with as much knowledge as possible. Language learning is a process of developing the awareness of the world, and learning cultural knowledge is an important way for us to enrich learner's knowledge.

Teaching culture is considered important by most teachers but it has remained insubstantial and sporadic in most language classroom (Omaggio, 1993). It is clear that cultural background knowledge is necessary in language teaching. Teachers should use different methods to help students to overcome the difficulties in language learning as well as culture learning. However, it is not easy to teach culture knowledge. Teachers must be acquainted with the differences between linguistic cultures. Teachers can provide cultural information, and teach students to express themselves correctly in different occasions. The key point is how to perform different ways in teaching different cultures. This paper presents some of methods related to the cultural aspects of practical techniques that have been found to be effective in culture-based language teaching and a few tips that can help to make the teaching of culture a better experience for both teachers and students.

\section{CReating Beneficial Cultural ConteXts}

It goes without saying that a total immersion in the culture of a native speaking country seems to be the first preference for learning its culture. But it does not follow that students cannot learn a foreign culture in the classroom in our home culture. Teachers may as well create an environment in an economic and systematic way. Through the procession of comprehensible classroom communicative activities, culture learning is gradually pushed forward.

Both language and culture teaching involve the development of a feeling for language in both written and spoken discourse. However, some approaches being complimented in our classroom have not always served to develop such responses to language or to isolate the different kinds of responses involved. On one hand, the structural approaches to ELT, with their emphasis on discrete-point teaching, "correctness" in grammatical form and repetition of a range of graded structures, restricted lexis, etc., still represents a dominant methodology hindering culture teaching. On the other hand, the teaching culture has lacked a consistent methodology of representation to non-native Chinese students. Therefore, an effective approach is badly needed where language and culture study are more closely integrated and harmonized than is commonly the case now.

With the purpose of a better cultural acquisition from language teaching, teachers can adopt an effective method on cultural texture. Oxford (1994) has used the term 'cultural texture' to describe the many aspects of culture that teachers 
need to teach to their students. To achieve this texture, teachers need to vary three different parameters, i.e. information sources, activity-types and positive interactions.

\section{A. Various Information Sources}

First of all, teachers should encourage students to collect information, and they can use encyclopedias, multimedia software and the internet for the required material. Students will try every means possible to get the knowledge themselves instead of waiting for it. In addition, they will analyze the information and select what material best fits their cultural topics.

In order to get a comprehensive picture of the target culture from many angles, teachers need to present their students with different kinds of information by accumulating a great deal of courseware. The list below shows some possible sources of information which can be used as materials for teaching culture. By using a combination of visual, audio and tactile materials, teachers are also likely to succeed in addressing the different learning styles of their students.

\begin{tabular}{|l|l|l|}
\hline extracts from literary & \multirow{5}{*}{ internet } & multimedia software \\
\cline { 1 - 1 } films \& TV & Information & DVD \& CDs \\
\cline { 1 - 1 } encyclopedias & Sources & illustrations \\
\cline { 1 - 1 } literature & & video \\
\cline { 1 - 1 } background information & & newspapers, magazines \\
\cline { 1 - 1 } anecdotes & & interviews \\
\cline { 1 - 1 } & & photographs \\
\hline fieldwork & plays \& songs \\
\hline
\end{tabular}

The fast development of new media technologies (such as VCD, DVD, DTV, MP5, PlayStations, Visual Presenter, PowerPoint, Internet and Intranet) has begun to usher in new approaches to classroom management. The teachers have to learn to adapt themselves to this new revolution in media technologies with reference to the designing and teaching of cultural studies course.

\section{B. Various Activity Types}

The effective classroom activities can be characterized in many norms. The most common is the topic (i.e. what it is about), and the activity, (i.e. what it involves doing). In one aspect, information must be transmitted, regardless of how it is done. Participants also usually know what they are talking about. They have to ensure that they are "on topic" or "to the point". In another aspect, they exchange ritual talk in order to establish or maintain social relationships, like daily greetings. Or they are given instructions or guidance to accomplish a task. So they know what activity it is, and then act as other participants. Otherwise they would be confused, be misunderstood and embarrassed and furthermore communication would end up in failure. In a word, transmission of information is of vital importance. Here are some of the effective classroom activities below.

\section{Conducting topic-oriented activity}

As we all know, a topic is not a topic until it is talked about, so the teacher presents an issue where an existing element in the real world is concerned. Usually a single issue or related topic are talked about by cooperation of participants - teachers and students in the classroom. Inside or outside the classroom students take turns to talk about a topic in the sense of their cultural principles and norms. The teacher would adjust them to the target culture when he or she finds them misled by their own cultural background. The topics of issues in discussion vary considerably across cultures. In dealing with the topics, students are instructed to cross the cultural border between their own every day world and the world of the target language and follow certain social constraints and rules during participation of classroom activities, at the same time, the teacher may insert comments of a topic nature into an activity.

\section{Taking activity logs}

An activity log refers to the use of a notebook in which students write about experiences both in and out of classroom or record responses and reactions to cultural learning and to classroom activities. Activity logs provide students with an opportunity to reflect on learning, and are usually shared with the teacher on a regular basis but not graded. In this way, the teacher may be able to find out how the student is progressing and the students gain additional opportunities to practice writing. In teaching culture classes, activity $\log s$ may be used as a way of establishing a dialogue between teacher and student through comments, questions and reactions or a way of encouraging students to write regularly on topics of the activities.

By requiring them to evaluate class activity for interest cultural learning, students must reconsider what they have learnt. The teacher can also be provided useful feedback and each student also records his/her target for what they think they actually achieve, and their own comments on the activities. Considering the complexity of the course, it is essential for the teacher to instruct the students about activity logs. The note is also taken partly in class and partly outside class involving the different steps or periods of some topics and themes.

\section{Selecting authentic materials}

Selecting adaptive materials is an essential factor for students to improve their comprehension ability. A selection of authentic foreign material should be used, especially dialogues, because it's more authentic and reflects cultural 
behavior followed by speakers. Authentic materials can frustrate students lacking sufficient cultural and social knowledge of the target language, and therefore teachers should carefully select suitable materials to motivate their learning interests. Teachers should explain cultural factors encountered in the material. Students now have easier access to visual aids such as films and videotapes. It is generally agreed that what helps in cultural acquisition is to be shown regularly about cultural background. Dialogue is a large proportion of authentic listening materials. It provides a wide range of western culture, such as customs, habits, social manners, life style. So it is quite necessary for teachers to give students an introduction to help them understand well native speakers and their culture.

Through multimedia and network technology the teacher can offer students not only rich sources of authentic learning materials, but also an attractive and friendly interface, vivid pictures and pleasant sounds, which to a large extent overcome the lack of authentic language environment and arouses students' interest in learning. There are many good videos and texts published concerning the classic literacy works and most teachers have access to them and the video equipment. Watching videos is simply another tool for learning and enjoyment. Frequently, when some writer and his or her works are dealt with, especially the classic ones, the students should be offered the opportunity to enjoy the video. The teacher still can make use of the chances to work out some methods to arouse the curiosity and motivation.

\section{Employing prediction}

Prediction is a subskill in teaching, meaning that students use their knowledge about the language, what they are provided with (e.g. title, topic area), their worldly knowledge and experiences to foretell the listening or reading text's content and then confirm or repair their predicted content so that a better and effective understanding can be achieved. Prediction is not wild guessing, but a skill that needs sufficient foundations. Appropriate background knowledge like custom, geography, history, politics and sound awareness of cultural differences between languages can contribute to reasonable predictions. Language always occurs within a cultural and social setting of some sort, and it must be interpreted in the light of this social and cultural environment.

Students should be encouraged to set up useful predictions and activated relevant concepts and experiences in their minds. Some culture-specific features of the context or of the speaker's assumptions could mean that a lack of cultural knowledge in the students would affect comprehension. If full background information concerning key contextual features is provided, students can build up their own set of 'working stereotypes' relating to the foreign culture, increasing the efficiency of their predictive skill.

Taking prediction is a way to practice students to predict what they are going to learn. As mentioned above, prediction can be a useful tool especially in quizzes, but it can be equally useful in using almost any materials. Like 'noticing', prediction can engage the students more actively. For example, if the material comes on video, the teacher can ask students to watch TV with the sound off, to predict what is being said. Alternatively, stop the tape in the middle of an act and encourage the students to predict what happens next. This technique may be more efficient if computerized control is accessible. In addition, when the students are given the title of the reading and asked to predict what they will learn, they will be forced to review their existing knowledge of the topic and raise their curiosity about whether their prediction is correct or not.

\section{Doing research based learning}

This is a methodology that asks students to complete a task through research. Doking research is also the study of an event, problem or phenomenon using systematic and objective methods, in order to make students understand something better and to develop interests and theories about it. "To do research, one first needs to have a 'topic'. The topic may be a problem, a study, or an area to be investigated to find out more information or to confirm or disprove existing knowledge." (Liu Renqing, 2004, p. 243). The research program can big or small; it can be completed within a month or a day according to the level of difficulty; it can be done either in groups or by one person. An example of a task with a number of components is one in which students choose a topic that combines their interests with the classroom, collect material about it by searching the internet or library to find information on any aspect of the target-culture that interests them., compile that material into a booklet and give a presentation in the following class. Students can explain to the teacher or their group what they have learned and answer any questions about it. This can lead to poster-sessions or longer projects. For some students, it can even lead to a long-term interest in the target-culture.

Besides what haven been mentioned above, some other types of activity that have been found useful include the following: games, role play, field trips, reading activities, listening activities, writing activities, discussion activities, singing and so on, but with a bit of thought, most standard EFL activities can be easily adapted for use in the culture classroom. The most important point is to ensure that the students are actively engaged in the target culture and language.

\section{Positive Classroom Interactions}

Second language learning is a complex phenomenon with different variables concerning the social-cultural elements of the contexts, an interactional approach can ensure that a social perspective of second language development and instruction contributes to having a positive effect on the nature and quality of language learning, which activates the autonomous learning motivation and create diversity in the learning atmosphere. Classroom interaction can provide different selling points to create a positive cultural learning environment, such as: a wide diversity of opinions, references, values, many different experiences and cultural background. As Cullen puts it, selling points for culture 
means the feature of classroom teaching activities that make it attractive to students. In order to create cultural texture, teachers must be careful not to portray the culture as monolithic, nor to only teach the pleasant aspects. Activities and materials should portray different aspects of the culture. In other words, teachers need to 'sell' different views of the culture to their students. Introducing deliberate contrasts within a culture can be useful (Cullen, 2004). Some different teaching activities are contrasted below.

\begin{tabular}{|c|c|c|}
\hline Attractive & \multirow{8}{*}{ Vs. } & Shocking \\
\hline Similarities & & Differences \\
\hline Dark aspects of culture & & Bright aspects of culture \\
\hline Facts & & Behavior \\
\hline Historical & & Modern \\
\hline Old people & & Young people \\
\hline City life & & Country life \\
\hline Stated beliefs & & Actual behavior \\
\hline
\end{tabular}

The classroom interaction creates a positive mutual learning environment, so the rich dissimilar feedback will compel the teachers to adjust their teaching pedagogy in accordance with the students' demand and interest, evaluate students' receptive and productive competence, and develop classroom climate between teachers and students.

\section{TIPS ON TEACHING PRACTICE}

The best one of cultural learning approaches is to encourage an interactional, experiential learning concerned with the learners' own interest. To explore effective approaches of culture communication transmission in English classroom teaching, teachers are expected to help students build up the following relevant skills in culture comprehension and appreciation:

\section{A. Activities for Personalization}

Only by personalizing activities and content can teachers hope to lead students to better cultural understanding. The teacher can start off by talking about a distant country, but this will only result in stereotyping if he or she does not allow students to relate the same issues to their own lives. And as every language teacher knows, students love to talk about themselves. For instance, when discussing a new text or a topic, students can be asked to draw links to their real experiences of constructing similar events, situations and selves to make them respond to text worlds. Students can be encouraged to make use of their text-world experiences as a lens to create imaginative perspectives on their real-experiences by discussing conventional ways and then writing a true/imaginary story that might happen in their real lives. By elaborating on their real-world experiences, students discover certain beliefs and attitudes about that experience they use to interpret text-world experience (Beach, 1998). Obviously, by helping students make personal and inter-textual connections, these reader-responses methods engage them and increase the depth of their learning.

\section{B. Students'Autonomy in Group Work}

Students can learn autonomously more in group work. Throughout the activities, the students should be entirely autonomous: They decide their work partner, the topic, materials, presentation, audience involvement, etc. While working, the group members co-operate, influence, and simulate each other. There is more interaction among members because they assume different roles and share responsibilities. There is also a team spirit since they all work towards the same goal.

Each group of students decides their own presentation, which can best communicate their ideas to the class and get the whole class involve. They may present their materials through debate, lectures and short plays, simulate press conference, etc. They can use pictures, maps, charts, and video shows as visual aids. In this way, students can learn how to conduct basic interaction.

Besides, in this kind of activity, the group members must evaluate their own work by comparing their actual performance with what they prepare and expect. Then, their classmates will tell them directly their strengths and weaknesses. Lastly, the teacher should summarize the key points of the group's work. The prompt feedback not only makes the group see their problems, but also enables the other groups to become aware of the problems so they can avoid them and do even better.

\section{Scientific Reading Activities}

Teachers should introduce and produce cultural readers. Foreign culture acquisition cannot be achieved merely through classroom teaching. Students should have things to be read. Teachers should also prepare their lessons carefully, try to find reading materials with cultural information. There should be proper language-learning strategies such as checking comprehension with a partner, and reading groups of words instead of word-by-word - including throughout the text to help students look at their own learning process and build a repertoire of ways to become active learners, both during and after the course.

Reading is integrated with listening, speaking and writing. For this reason activities should become more varied and 
demanding. For example, students are initially asked to choose the best summary of a given story; later, they are asked to write their own summary. Here are some of the activities students can do:

\begin{tabular}{|l|l|l|}
\hline Before reading & While reading & After reading \\
\hline$\bullet$ discuss the topic & $\bullet$ match pictures with paragraphs & $\bullet$ react to the culture background \\
$\bullet$ interview their classmates & $\bullet$ mark the text for the topic or main idea & $\bullet$ check their predictions \\
$\bullet$ review what they already & $\bullet$ find evidence for a particular point of view & $\bullet$ identify facts vs. opinions \\
know about the topic & $\bullet$ look for answers to the pre-reading quiz & $\bullet$ compare issues cross-culturally \\
$\bullet$ take a quiz about the topic & $\bullet$ take notes or make an outline & $\bullet$ write or correct a summary \\
$\bullet$ predict the content of the reading & $\bullet$ write captions for pictures & $\bullet$ look for examples that support a point \\
\hline
\end{tabular}

These activities help students make sense of the readings, and then encourage them to use details from the readings to discuss contemporary issues. Almost all of the activities involve either pair-work or group-work, thus maximizing student-to-student interaction. When students work alone on an activity, they follow up by comparing answers with a partner. Thus, students have numerous opportunities to communicate in meaningful ways in a collaborative atmosphere.

\section{Cultural Interaction by Literature}

As most students of foreign languages struggle with a language and culture with which they are unfamiliar, literature which deals with either of these themes can be relevant to them. As said, literature cannot escape its cultural implications, and literature is a response to a relationship between the culture of the students and that represented by the current readers of literature being presented (Chen Ben, 2004). In this respect, literature is one among several means of access to the foreign culture background studies.

However, interaction with a literary text depends on a reader's familiarity with the cultural assumptions in it. Literature is a facet of culture. Its significance can be best understood in terms of its culture, and its purpose is meaningful only when the assumption it is based on are understood and accepted. To solve the problem, teachers are to help students develop competence in the understanding of the readings and arouse the students' interest in thinking deeply about the ideas expressed by the selected works and to relate these to their own experience.

\section{E. Design of Course Objectives}

When we study and compare cultures, we actually begin a search for our own identity. This introductory course hopes to help students better understand the culture that has formed us in relation to "other" cultures that have found 'others' by studying how one particular culture has itself been formed. Placing cultural texts in their social environments, this course will primarily introduce students to the international perspectives of comparative cultural studies in relation to other forms of presentation. This will enable us to appreciate how a particular form of writing encodes, transmits and questions cultural values and hence to understand the forces that shape our world.

Teachers must offer direct instruction of techniques or procedures for developing a cultural class through various classroom interactions, and they also should model an enthusiasm for and curiosity about the target culture through their own behaviors and attitudes. Teachers will automatically accumulate "teachable resources" throughout the day, point out interesting words or sentences as they crop up in texts, stories, or conversation; ask students to explore ways to express the topic and meaning; and help identify colorful, descriptive ways of speaking and writing in the material.

\section{CONCLUSION}

In summary, culture offers several benefits to language classes. It can be useful in developing linguistic knowledge, and, if duly motivated, extend students' language proficiency. Needless to say culture teaching is an essential supplement for language teaching, which enables students to experience pleasure from language learning. The learning of target-language culture can improve students' understanding of the target language, enrich their ability of understanding. Obviously learning target-language culture can reinforce students' understanding of the world and cultivate the cultural awareness.

Culture learning is informative, as well as interesting, which covers language, culture, custom, ethics, science, social issues, etc. Students are exposed to various information which appeals to their taste. And what they learn will be of great use in their daily life. As a result, their interest in learning and their motive and desire to communicate in foreign language will be aroused.

From the above illustration, we can know that an effective method and practical technique of teaching culture is very important in language teaching, so every teacher should realize its importance and necessity, and find some practical techniques to carry out culture teaching in language teaching. In a word, teachers should try their best to make good use any materials available and textures to provide students with more materials rich in cultural contents and more closely connected with their specialty.

\section{REFERENCES}

[1] Beach, R. (1998). Constructing Real and Text Worlds in Responding to Literature. Theory into Practice, Summer 98, Vol. 37, Issue 3. 
[2] Brian Cullen. (2004). Practical Techniques for Teaching Culture in the EFL Classroom. (I-TESL-J) http://iteslj.org/ Techniques/Cullen-Culture.html (accessed 23/07/ 2004).

[3] Chen Ben. (2004). Literature Teaching in ELT in China: Language, literature and culture. CELEA Journal, 4, 60-62.

[4] Gu Yueguo. (2000). Cross Cultural Communication. Beijing: Foreign Language Teaching and Research Press.

[5] Hamer, Jeremy. (2000). How to Teach English. Beijing: Foreign Language and Research Press.

[6] Hatim, Basil. (2001). Communication Cross Cultures. Shanghai: Shanghai Foreign Language Press.

[7] Hu Zhuanglin. (1998). Linguistics: A Course Book. Beijing: Peking University Press.

[8] Liu Renqing. (2004). Research for Gaining Knowledge. English Educational Research (1edn). Beijing: Foreign Language Teaching and Research Press, 235-249.

[9] Nida, Eugine A. (2001). Language and Culture: Contexts in Translating. Shanghai: Shanghai Foreign Language Press.

[10] Omaggio-Hadley, A. (1993). Teaching Language in Context. Boston. MA: Heinle \& Heinle Publishers.

[11] Oxford, R. L. (1994). Teaching Culture in the Language Classroom: Towards a new philosophy. In J. Alatis (ed), Georgetown University Round Table on Language and Linguistics 1994 (pp. 26-45). Washington DC: Georgetown University Press.

[12] Seelye, H. N. (1993). Teaching Culture: Strategies for Intercultural Communication ( $2^{\text {nd }}$ ed.). Lincolnwood, Ill: National Textbook Company.

Lili Dai was born in Beijing, China in 1957. She received her B.A. degree in English Education from Shannxi Normal University, China in 1992.

She has been teaching College English since 1995, and is currently a professor in Department of Language and Culture in the Teachers College of Beijing Union University, Beijing, China. Her research interests include the study of second and foreign language learning and teaching.

Prof. Dai is a member of the Beijing College English Teaching Research Association of China. 